\title{
Agricultura familiar e desenvolvimento sustentável: uma caracterização da feira do produtor rural do município de Marechal Cândido Rondon - Paraná, Brasil
}

Family agriculture and sustainable development: a characterization of the rural producer fair in the municipality of Marechal Cândido Rondon - Paraná, Brasil

Agricultura familiar y desarrollo sostenible: una caracterización de la feria de productores rurales en el municipio de Marechal Cândido Rondon - Paraná, Brasil

Ethol Exime

ORCID: https://orcid.org/0000-0002-6962-8088 Universidade Estadual do oeste do Paraná, Brasil E-mail: eeetholl@hotmail.com

Cleoson Moura dos Reis ORCID: https://orcid.org/0000-0002-8490-6357 Universidade Estadual do oeste do Paraná, Brasil E-mail: cleosonmoura@gmail.com

Mariell Lima Costa

ORCID: https://orcid.org/0000-0002-4292-9673 Universidade Estadual do oeste do Paraná, Brasil E-mail: mariell_lima@hotmail.com

Aline Costa Gonzalez

ORCID: https://orcid.org/0000-0001-9672-8562 Universidade Estadual do oeste do Paraná, Brasil E-mail: alinecg_15@hotmail.com

Juscelino Martins Costa Junior ORCID: https://orcid.org/0000-0001-6166-6461 Universidade Estadual do oeste do Paraná, Brasil E-mail: juscelinojunio_@hotmail.com

Wilson João Zonin

ORCID: https://orcid.org/0000-0002-3364-5599 Universidade Estadual do oeste do Paraná, Brasil E-mail:wzonin@yahoo.com.br

\begin{abstract}
Resumo
As feiras livres são importantes vetores para o desenvolvimento rural na agricultura familiar, sendo uma estratégia para enfrentar dificuldades relacionadas à comercialização. Esta pesquisa visa caracterizar a feira do agricultor rural de Marechal Cândido Rondon/PR e propiciar um olhar sobre suas potencialidades e limitações. Para isso foi realizado entrevista com questões abertas e semiabertas, aplicadas ao presidente da feira e a doze consumidores. Foi utilizada também, como ferramenta para o estudo, a Matriz FOFA (Fortalezas, Oportunidades, Fraquezas, Ameaças) ou Análise SWOT (Strenghts, Weaknesses, Opportunities e Threats); e o Diagrama de Venn. A análise da matriz revelou que a organização da feira é a principal fortaleza encontrada, enquanto a infraestrutura é fraqueza. A feira tem grandes oportunidades, principalmente na sua divulgação, entretanto, apresenta a falta de apoio dos órgãos de Assistência Técnica e Extensão Rural como principal ameaça. Apesar dos agricultores terem grande satisfação nesse modelo de comercialização de circuito curto, há ausência de investimento pelo poder púbico local. A potencialidade marcante é o processo organizacional na feira, e como limitação, observou-se a falta de diálogo efetivo entre sua diretoria e os órgãos municipais, tema que pode ser pesquisado em futuros estudos relacionados. Nota-se que investir na feira livre de Marechal Cândido Rondon é incentivar não somente os agricultores familiares que atuam nas vendas, mas também consolidar a importância da classe para a alimentação saudável da cidade.
\end{abstract}

Palavras-chave: Circuitos curtos; Comercialização; Solidariedade.

\begin{abstract}
Free trade fairs are important vectors for rural development in family agriculture, being a strategy to face difficulties related to commercialization. This research aims to characterize the rural farmer fair of Marechal Cândido Rondon/PR and provide a look at its potentialities and limitations. For this purpose, an interview was conducted with open and semi-open questions, applied to the president of the fair and twelve consumers. It was also used as a tool for the study, the Matrix FOFA (Strengths, Opportunities, Weaknesses, Threats) or SWOT Analysis (Strenghts, Weaknesses, Opportunities and Threats); and the Venn Diagram. The matrix analysis revealed that the organization of the fair is the
\end{abstract}


main strength found, while the infrastructure is weakness. The fair has great opportunities, especially in its dissemination, however, presents the lack of support from Technical Assistance and Rural Extension agencies as the main threat. Although farmers are very satisfied with this short circuit commercialization model, there is a lack of investment by the local public power. The remarkable potential is the organizational process at the fair, and as a limitation there is a lack of effective dialogue between its board of directors and municipal bodies, a subject that can be investigated in future related studies. It is noted that investing in Marechal Cândido Rondon's free trade fair is to encourage not only family farmers who work on sales, but also to consolidate the importance of the class for the city's healthy food.

Keywords: Short circuits; Commercialization; Solidarity.

\section{Resumen}

Los mercados abiertos son vectores importantes para el desarrollo rural en la agricultura familiar, siendo una estrategia para enfrentar las dificultades relacionadas con la comercialización. Esta investigación tiene como objetivo caracterizar la feria de agricultores rurales en Marechal Cândido Rondon / PR y proporcionar una mirada a sus potencialidades y limitaciones. Para ello, se realizó una entrevista con preguntas abiertas y semiabiertas, aplicadas al presidente de la feria y doce consumidores. También se utilizó como herramienta para el estudio, la Matriz FOFA (Fortalezas, Oportunidades, Debilidades, Amenazas) o Análisis FODA (Fortalezas, Debilidades, Oportunidades y Amenazas); y el diagrama de Venn. El análisis de la matriz reveló que la organización de la feria es la principal fortaleza encontrada, mientras que la infraestructura es la debilidad. La feria tiene grandes oportunidades, principalmente en su difusión, sin embargo, presenta como principal amenaza la falta de apoyo de los órganos de Asistencia Técnica y Extensión Rural. Aunque los agricultores están muy satisfechos con este modelo de comercialización de cortocircuito, no hay inversión por parte de las autoridades públicas locales. El potencial llamativo es el proceso organizativo de la feria, y como limitación, hubo una falta de diálogo efectivo entre su junta y los órganos municipales, tema que puede ser investigado en futuros estudios relacionados. Se observa que invertir en el mercado libre de Marechal Cândido Rondon es incentivar no solo a los agricultores familiares que trabajan en ventas, sino también a consolidar la importancia de la clase para la alimentación saludable en la ciudad.

Palabras clave: Cortocircuitos; Comercialización; Solidaridad.

\section{Introdução}

A história da humanidade está inteiramente ligada à agricultura, desde a revolução agrícola, quando os homens deixaram de ser nômades e aprenderam a semear e produzir seu próprio alimento, até a história recente, com uma agricultura cada vez mais moderna e tecnológica, com inserção de insumos produtivos, como agrotóxicos e adubação química, em um processo de produção que visa apenas o resultado e o lucro que ela gerará (Baiardi, 2014).

Entre 1960 e 1970, com a Revolução Verde, o Estado em um processo de modernização, acabou focando seus investimentos nos agricultores de grande porte, favorecendo um processo injusto no campo, onde poucos latifundiários eram atendidos pelos investimentos tecnológicos do governo e muitos minis fundiários não. Esse processo resultou no êxodo rural e na invisibilidade do agricultor de pequeno porte.

Os investimentos na agricultura de pequeno porte no Brasil só começam a acontecer no início da década de 90, quando diversas entidades sociais começaram a se manifestar no intuito de visibilizar essa classe, e é nesse período que surge a agricultura familiar, com ensejo de valorizar o agricultor, que por muito tempo foi esquecido pelo Estado. Em 1996 cria-se o Programa Nacional de Fortalecimento da Agricultura Familiar - PRONAF, sendo um marco para as políticas públicas na agricultura brasileira (Wanderley, 2000).

De acordo com Moreira (2007), na agricultura familiar, o trabalho, a administração, as decisões sobre o que e como produzir, bem como os investimentos, são realizados pelos membros de uma família, sendo ou não, os proprietários da terra. É necessário que as prefeituras reconheçam na agricultura familiar, uma maneira de gerar desenvolvimento local e de ampliar pequenos negócios, visto que se essas famílias puderem produzir e comercializar, gerarão renda e tributos para os municípios (Esquerdo, Bergamasco \& Andrade, 2013).

Embora já se reconheça a importância da agricultura familiar, seja ela a social, ambiental, cultural ou econômica, ainda é possível perceber as dificuldades vivenciadas pela categoria, como a ausência de canais de comercialização, que dificultam o desenvolvimento social dos agricultores (Oliveira, 2016; Buainain, 2006). 
Os canais de comercialização da agricultura familiar começaram a ser ampliados nos últimos vinte anos, juntamente com o processo de valorização do agricultor familiar, principalmente com as feiras livres, fruto de uma mobilização dos movimentos sociais pelo Brasil.

As feiras livres surgem como uma oportunidade de comercialização nos circuitos curtos, fortalecendo não somente o produtor familiar, mas também seu cliente, com uma alimentação mais justa socialmente, ambientalmente sustentável e economicamente positiva. Através dessas, o agricultor familiar consegue não apenas um aumento na sua renda e produção, mas criar laços de cooperação junto aos outros agricultores, sem estabelecer concorrência e sim, uma cadeia onde todos possam se ajudar.

Segundo Pereira et al. (2017, p.2) "a feira pode representar um lugar de preservação das relações socioculturais, dos aspectos peculiares ao ambiente rural, da autonomia do (da) agricultor (a) e do fortalecimento dos laços e do saber local". Portanto, incentivar as feiras livres é consolidar o desenvolvimento social dos agricultores familiares, além de engrandecer o desenvolvimento rural dos municípios.

A região Sul do país é tradicionalmente marcada pelo cooperativismo e pela comercialização de produtos familiares em feiras livres, no entanto ainda se observa a necessidade de uma maior divulgação das suas atividades, com ensejo tanto de valorizar os agricultores feirantes, como motivarem os clientes. Nesse contexto, o trabalho visa caracterizar a feira do agricultor rural de Marechal Cândido Rondon/PR e propiciar um olhar sobre suas potencialidades e limitações.

Para tanto, o artigo apresenta mais quatro seções, além da introdução; primeiro um referencial teórico, destacando conceitos sobre agricultura familiar, circuitos curtos de comercialização e desenvolvimento sustentável; a seguir, uma caracterização da metodologia da pesquisa; na terceira seção, os resultados e discussão, com um olhar histórico da feira, além de uma análise da sua infraestrutura, comercialização e marketing, e das suas Fortalezas, Oportunidades, Fraquezas e Ameaças; e para finalizar, discutiremos as considerações gerais do artigo, fazendo um paralelo entre as seções anteriores.

\section{Referencial Teórico}

O referencial fundamenta-se teoricamente nos conceitos de "agricultura familiar", "circuitos curtos de comercialização" e "desenvolvimento sustentável”. Esses aportes teóricos são necessários para contextualizar e consequentemente aprofundar conhecimento sobre o tema.

\subsection{Agricultura Familiar}

A agricultura intensiva tem dado sinais extenuantes, que se baseia no uso excessivo de recursos naturais e força de trabalho farta e barata, determinando a elevação dos custos sociais e de produção. Assim, sistemas alternativos de produção, como a agricultura familiar, vem sendo opção para a garantia de alimentos seguros, combate à pobreza, conservação ambiental e manutenção do pequeno agricultor no campo (Lago et al., 2006).

De acordo com a Lei da Agricultura Familiar no 11.326/2006, o que define o agricultor familiar, é que ele trabalhe no meio rural, não tenha área maior do que quatro módulos fiscais, que a renda principal seja resultado da produção agrícola da propriedade e que utilize predominantemente mão-de-obra da própria família para desenvolver o trabalho no campo (Brasil, 2006).

Embora a agricultura familiar enfrente dificuldades contra a agroindústria tradicional, é de suma importância a sua contribuição na receita do país, cuja representação é de 38\% do valor da produção e $34 \%$ do total das receitas do agronegócio brasileiro. Estes dados mostram que se deve valorizar e investir na agricultura familiar, já que ela vai além da produção para autoconsumo e abastecimento interno do consumo de alimentos no Brasil (Schneider \& Cassol, 2013). 
De acordo com Lago et al. (2006), percebe-se um aumento da produção familiar a partir do acréscimo de consumidores para seus produtos. Este feito se deu através da mudança de comportamento das diversas pessoas, que ao longo do tempo vem adquirindo consciência de preservação ecológica e a busca por uma alimentação cada vez mais saudável. Visto que, ao utilizar bases tradicionais, alternativas sustentáveis para a produção, sem uso de agrotóxicos, beneficiar a região local como um todo, fornecer um produto mais saudável com preços mais baixos, faz essa agricultura surgir como uma maneira diferente de se pensar, respeitando o meio ambiente e preservando os recursos naturais (Guillen et al., 2020). Os bens da agricultura familiar vão além das questões econômicas e ambientais, prezando por uma melhoria na vida de todos. Uma dessas questões é a de comercializar alimentos mais saudáveis e isso pode ocorrer através da venda direta, conhecida como circuitos curtos de comercialização.

\subsection{Circuitos Curtos de Comercialização}

As redes alternativas de comercialização surgem com o intuito de fortalecer os modelos tradicionais de mercado, bem como a agricultura familiar. Darolt et al. (2016) diz que o principal objetivo dessas redes, é fugir dos padrões produtivos e mercantis impostos pelo sistema industrial. As redes alternativas originam-se a partir do questionamento do modelo agroalimentar dominante e representam esforços, para ressocializar as relações de produção e consumo de alimentos (Jarosz, 2008).

Conforme Messmer (2013), a definição de circuitos curtos oficial que foi estabelecida em 2009 na França, determinou esses circuitos como sendo práticas de comercialização de produtos de origem agrícola, executadas a partir do produtor e consumidor (de forma direta), ou com a mediação de até um intermediário. Para Darolt et al. (2016, circuitos locais, curtos ou alternativos, são compreendidos como uma relação de troca, que aponta para uma proximidade entre consumidores e produtores, via comercialização direta, como de uma cooperativa, eliminando outros elos de intermediação na cadeia ou indireta, via loja especializada, restaurante etc.

Silva (2015) diz que, os circuitos curtos de comercialização são vetores importantes para a emancipação socioeconômica de agricultores e agricultoras, em especial os familiares. Onde a Organização das Nações Unidas para a Alimentação e a Agricultura (FAO) acredita que esses circuitos são fundamentais para o fortalecimento dos sistemas de produção da agricultura familiar (Cepal, 2014).

Através da busca pela aproximação dos locais de produção com o de consumo de bens e serviços, os circuitos proporcionam a otimização logística que poupa a realização de esforços que acaba sendo desnecessário, como: redes de transporte, energia, combustível, embalagens, intensificação de tráfegos, entre outros, que são estrategicamente elaborados para potencializar o domínio do setor por determinados agentes e atravessadores econômicos (Oliveira, 2018).

Os circuitos curtos de comercialização, especialmente as feiras livres, são estratégicas e promissoras na efetivação do escoamento da produção de muitos agricultores familiares. Conforme Pierri e Valente (2015), as feiras livres são caracterizadas por ocorrerem em espaços públicos e de forma periódica, são locais onde ocorrem trocas de mercadorias entre produtores, além de propiciar o escoamento da produção agrícola local.

Os agricultores vendem uma diversidade enorme de produtos provenientes das hortas, dos pomares, bem como, produtos de suas indústrias domésticas rurais, como queijos, geleias, doces e requeijão. Esta diversificação na produtividade garante a participação constante deles nas feiras e aumenta a gama de consumidores (Pereira et al., 2017).

Nesse contexto, Buainain e Batalha (2007) relatam que os circuitos curtos de comercialização são ferramentas que podem estimular essa dinâmica de aproximação, ampliando assim a relação entre campo e cidade. E dessa forma, revalorizar os espaços rurais, auxiliando na construção de novos paradigmas de consumo, além de propiciar condições para uma maior 
autonomia dos agricultores e agricultoras familiares, fortalecendo assim, a identidade de produtos locais, gerando benefícios econômicos, ambientais e socioculturais.

Desse modo, as feiras livres, além de gerar trabalho e renda no campo, estimula a economia local e possibilita a soberania e segurança alimentar para a população urbana, de forma que os agricultores participem como protagonistas de todo processo de desenvolvimento sustentável (Pereira et al., 2017).

\subsection{Desenvolvimento Sustentável}

$\mathrm{O}$ auge da revolução verde foi baseado no modelo de utilização de semente modificada, que trouxe o uso extensivo da tecnologia na produção agrícola. Essa modernização aumentou consideravelmente a produção de países em desenvolvimento e ainda levou a diminuição de alguns custos, como o de manejo.

Toda essa modernização auxiliou para que atualmente, no mundo, tivéssemos esse crescimento na produção agrícola, que caso contrário, "estaria vivendo uma grave crise de desabastecimento" (FAO, 2012). Além dessa evolução na agricultura, trouxe o problema das questões de degradação ambiental e a limitação para resolver o problema da fome no mundo como seu principal objetivo. Isso faz com que apenas os grandes produtores detenham o poder dos grandes pacotes tecnológicos, alterando a cultura dos pequenos proprietários, inviáveis economicamente (FAO, 2012).

A partir desse momento de degradação ambiental, começou-se a pensar nas questões ambientais na agricultura. Assim surgiu a combinação do tema desenvolvimento rural e sustentabilidade, em 1970, com intuito de contrabalançar os efeitos negativos, principalmente sobre os países do terceiro mundo. Logo após esse período, vimos a criação do Programa das Nações Unidas para o Meio Ambiente (PNUMA) em 1972 (ONU, 2020), que tem como objetivo, trabalhar para manter os problemas do meio ambiente sob constante monitoramento, a fim de alertar as populações sobre esses problemas. Caporal e Costabeber (2004) apresentaram um estudo com eventos entre 1962 e 2002, na conferência Rio+10, em Joanesburgo, alertando sobre a saúde do meio ambiente. Nele, os autores definem o conceito de desenvolvimento sustentável como "o manejo e a conservação da base dos recursos naturais e a orientação da mudança tecnológica e institucional, de maneira que assegure a contínua satisfação das necessidades humanas das atuais e futuras gerações" (Caporal \& Costabeber, 2004, p. 101).

Como eixo principal, o desenvolvimento sustentável traz melhoria da qualidade de vida humana, sem exceder os limites da capacidade de suporte dos ecossistemas (Assis, 2006). Sob esse aspecto, a sustentabilidade, pela ótica da agroecologia, é vista como sendo capaz de manter um agroecossistema sócio ambientalmente produtivo ao longo do tempo. Dessa forma, a promoção do desenvolvimento rural sustentável deve-se relacionar com as seis dimensões advindas da agroecologia, que são, ecológica, econômica, social, cultural, política e ética (Caporal \& Costabeber, 2004).

Em outra perspectiva, o acesso ao desenvolvimento rural sustentável passa pela reconstrução de novos territórios, ou seja, na capacidade que terão os atores econômicos locais, em manejar e valorizar ativos específicos de cada região. Assim, pela ótica territorial, esse desenvolvimento não pode ser imposto, mas sim construído por indivíduos e por políticas públicas adequadas, a fim de estimular e mobilizar todos os envolvidos (Pecqueur, 2005).

\section{Material e Métodos}

Nos materiais e métodos apresentamos uma caracterização da área estudada e uma apresentação dos instrumentos metodológicos usados na pesquisa. Essa seção tem a função de ambientar o leitor sobre as condições que o estudo foi realizado. 


\subsection{Caracterização da área}

A Feira do Produtor Rural está localizada no município de Marechal Cândido Rondon. O referido município está localizado no extremo oeste do Paraná, integrando a Mesorregião Oeste Paranaense ( $\left.n^{\circ} 6\right)$ e a Microrregião de Toledo $\left(n^{\circ} 22\right)$, conforme representado na Figura 1. Apresentando como principais coordenadas geográficas $24^{\circ} 33^{\prime} 22^{\prime \prime} \mathrm{S}$ e $54^{\circ} 03^{\prime} 24^{\prime \prime} \mathrm{W}$ (Ipardes, 2020).

Figura 1 - Mapa de Localização da Feira do Produtor Rural de Marechal de Cândido, Rondon.
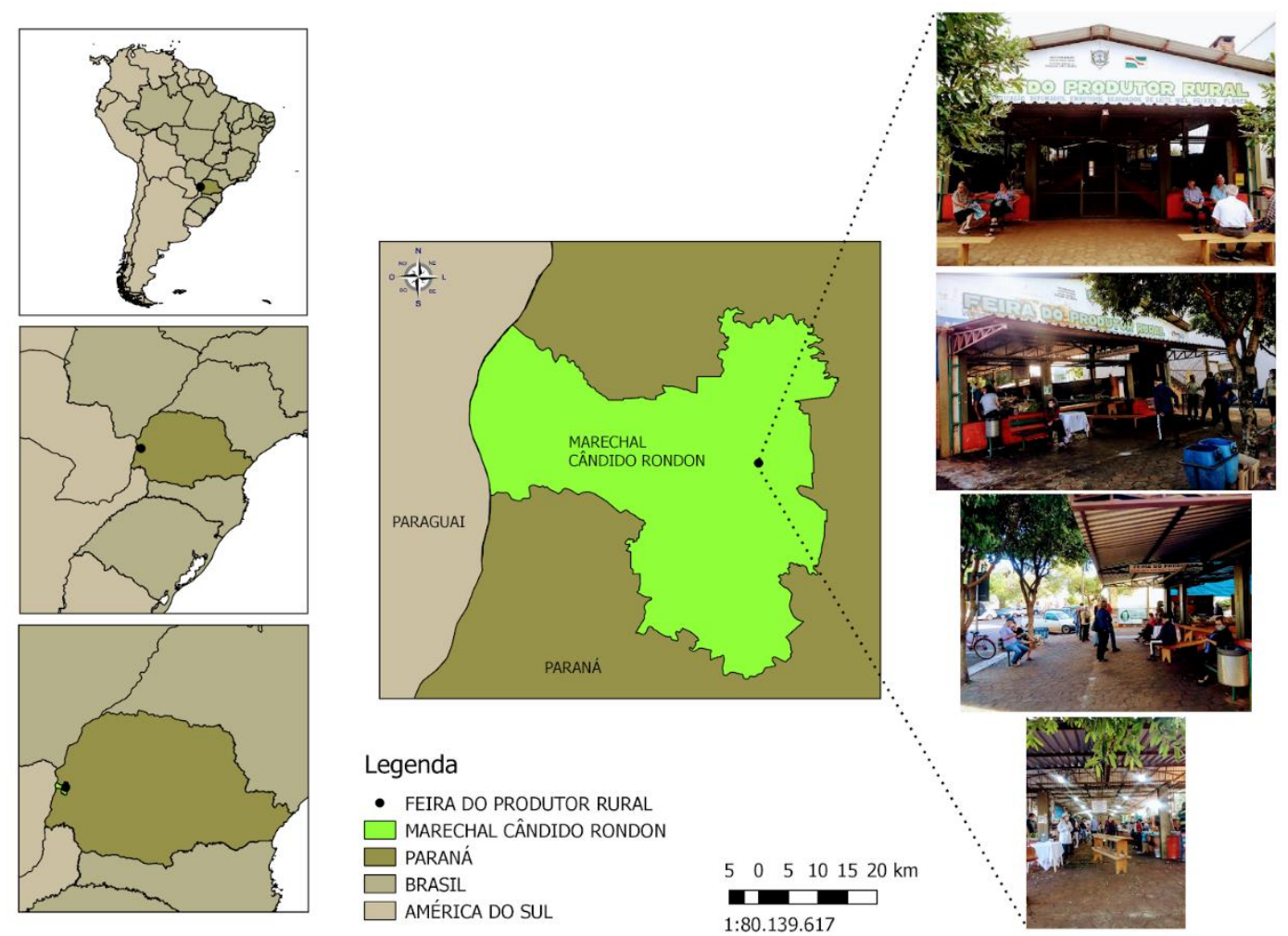

Dados: IBGE, 2010; Google Earth Pro (2020). Fonte: Autores (2020).

Segundo a estimativa do IBGE (2019), Marechal Cândido Rondon possui uma área territorial de 745,243 km², com uma população de aproximadamente de 52.944 habitantes. Conforme o censo demográfico de 2010, o município possuía 46.819 habitantes, no qual 83,61\% residiam em área urbana e 16,39\% residiam em área rural.

\subsection{Instrumentos Metodológicos}

Esse artigo é resultado em um estudo exploratório, que usou como forma de investigação o estudo de caso (EC), segundo Pereira et al (2018, p.70) "EC é uma metodologia de estudo de fenômenos individuais ou, processos sociais. Há uma gama muito grande e variada de estudos que se classificam na categoria metodológica dos EC". Fundamentado no estudo de Luciano (2017), foi elaborado um formulário composto por 13 perguntas e aplicado em forma de entrevista gravada, com o intuito de obter informações sobre questões históricas e estruturais da feira do Produtor Rural de Marechal Cândido Rondon. Essas questões foram divididas em duas categorias sendo, abertas e semiabertas. A aplicação do formulário foi dirigida ao presidente da feira e ocorreu no dia 26 de junho de 2020. Além disso, um formulário com 5 questões foi aplicado a 12 consumidores da feira, no dia 16 de junho do mesmo ano. A partir das respostas obtidas, os dados coletados foram organizados para análise. 
O método utilizado no estudo foi articulado entre o dedutivo e o indutivo (GIL, 2008), utilizando também a abordagem qualitativa, sendo que ao "analisar os conteúdos a fim de tirar partido de um material qualitativo, é frequentemente necessário entrevistas relativas ao questionamento" inicial (Bardin, 2011, p. 65).

Além disso, visando melhor compreensão entre a relação do ambiente interno e externo à feira, utilizou-se as ferramentas Matriz FOFA (Fortalezas, Oportunidades, Fraquezas, Ameaças), também conhecido como Análise SWOT (Strenghts, Weaknesses, Opportunities e Threats), e o Diagrama de Venn. Segundo Kummer (2007), através da FOFA, pode ser detectada as fortalezas e fraquezas, as oportunidades e ameaças de uma organização. Por sua vez, o Diagrama de Venn, possibilita verificar e caracterizar as relações com as instituições e grupos existentes (Kummer, 2007).

\section{Resultado e Discussão}

\subsection{Histórico}

Conforme o entrevistado, a Feira possui 29 anos de história, foi iniciada e estruturada com o intuito de que o produto do agricultor rural de pequeno porte, pudesse ser despachado de forma direta para o consumidor, garantindo assim um intercâmbio entre os habitantes da cidade com os produtores rurais.

No que se refere à localização do espaço, inicialmente a feira localizava-se ao ar livre na Praça Willy Barth, próximo à prefeitura do município de Marechal Cândido Rondon. Somente anos depois (há aproximadamente 25 anos), passaram a utilizar o espaço atual da feira, localizado na Rua do João VI, nº 911. Antes da construção do local (denominado pelo entrevistado de barracão), a estrutura era limitada. Com o aumento da feira, assim como também o número de clientes, os problemas na estrutura passaram a ser ainda mais evidentes. Sendo assim, a construção do barracão foi incluída no orçamento do município, realizada em 2008.

Em 2019, em cumprimento da lei municipal $n^{\circ} 4753$ (06/04/2015), um dos fundadores da feira do produtor rural, Germano Hardke, foi homenageado postumamente com uma placa, no qual a feira passou a ser denominada como Feira do Produtor Rural Germano Hardke, como observado na Figura 2. Conforme Burin (2010), a produção orgânica no município de Marechal Cândido Rondon teve início com Germano Hardke, na década de 60, em uma propriedade de apenas 0,5 ha. O produtor deixou um importante legado no município, tendo se tornado o símbolo da produção ecológica (Rede de Agricultura Sustentável, 2019).

Figura 2 - Placa denominando a Feira do Produtor Rural Germano Hardke.

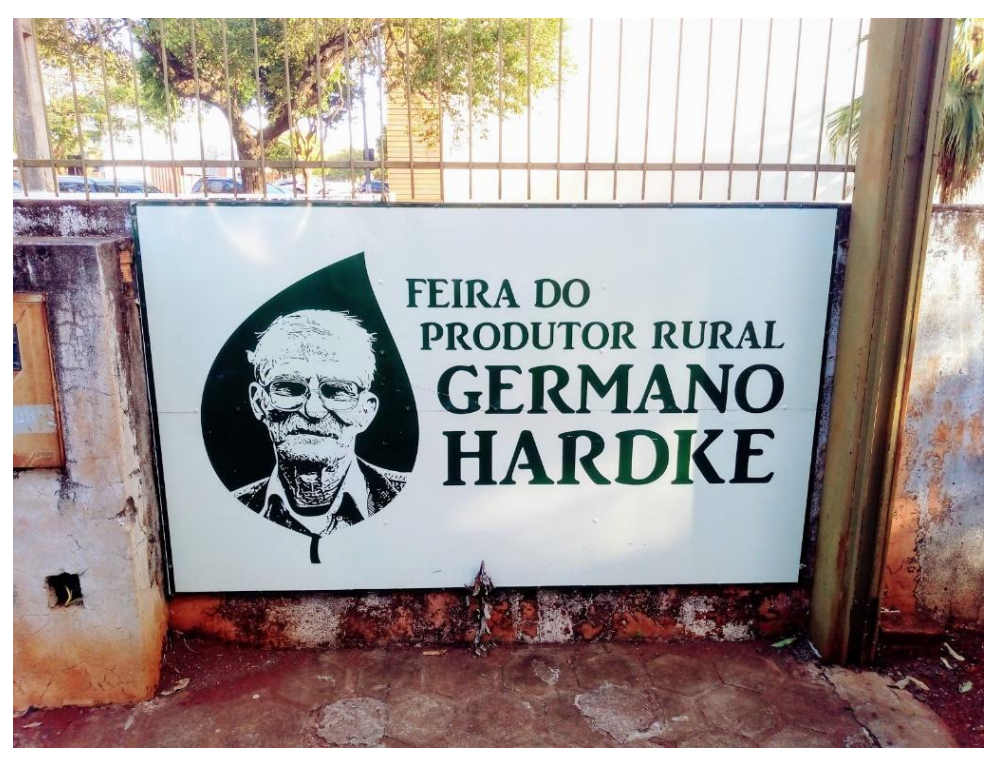

Fonte: Autores (2020). 
Tratando-se de aproximação e seleção dos agricultores que fazem parte da feira, de acordo com o entrevistado, esta etapa foi realizada pela Emater (Instituto Paranaense de Assistência Técnica e Extensão Rural - Unidade Marechal Cândido Rondon), com a localização dos agricultores familiares, mediante visitas. O espaço de cada feirante no barracão é permanente até o momento que os agricultores tiverem condições de continuar com suas atividades. No caso, se algum membro desejar desvincular-se, o espaço (que era do feirante) passa a ser do grupo da feira.

\subsection{Infraestrutura}

A feira é regida por um estatuto social e um regimento interno, os quais normalizam a atuação dos produtores, gerando uma maior organização entre os feirantes. Além dessa estrutura em sua legislação, para o bom funcionamento da feira, são necessários dois pontos importantes: A estrutura física e os serviços de acompanhamento de produção e comercialização.

O barracão que foi disponibilizado pela prefeitura para os feirantes, foi um ponto importante para o desenvolvimento da feira, porém o governo municipal tem em seu poder um documento que assegura a existência de, apenas uma concessão do uso e não uma doação, podendo ser retirada a qualquer momento. Apesar do barracão ser disponibilizado pela prefeitura, o lote utilizado por eles é disponibilizado pelo sindicato patronal dos agricultores. A necessidade de uma melhor infraestrutura apresenta um desafio importante para a feira, já que deve existir uma rede de contribuição entre a prefeitura e o sindicato, porém segundo o presidente da feira, não existe uma motivação por parte dos mesmos, mas que por parte dos feirantes, há a necessidade de um aumento do lote e consequentemente do barracão onde está localizado a feira.

O espaço inicial por feirante era muito pequeno, sendo um dos motivos para a não inserção de outros agricultores, já que aconteceu uma diminuição dos iniciais 24 feirantes para 16. Segundo o presidente da feira, existe por parte dos agricultores um receio em se inserir na feira, pela falta de auxílio, pelas burocracias e pela inferiorização que o sentido da palavra tem no município, gerando um certo medo aos membros da classe.

Assim, é possível perceber que existe uma necessidade de valorizar a agricultura de pequeno porte no município, e este é um trabalho que deve ser feito em uma aliança de responsabilidades, entre a sociedade civil, organizações não governamentais e o Estado. Uma consequência disso é a falta de um trabalho efetivo de Assistência Técnica e Extensão Rural (ATER) destinada aos feirantes, até para fomentar características importantes para a feira como o cooperativismo, a policultura e aspectos relacionados à comercialização. Ainda que a Universidade Estadual do Oeste do Paraná, juntamente com órgãos de ATER, como a CAPA e a ACEMPRE façam trabalhos com membros da feira, essas são atividades pontuais e atualmente não tem nenhum projeto em execução. Corroborando com isso, Tauk Santos (2000) cita que para alcançar o desenvolvimento local, é necessário promover mudanças positivas em prol de culturas populares e para isso, os serviços de ATER são primordiais.

Sobre os horários e funcionamento da feira, no início era sábado de manhã. Com o passar do tempo, um levantamento feito possivelmente pela UNIOESTE, a respeito da preferência de funcionamento da feira, resultou na mudança para as sextasfeiras a tarde. Posteriormente, outra pesquisa foi feita no intuito de acrescentar mais um dia de feira na semana, sendo escolhida então pelo público, a terça-feira, também no período da tarde.

Além disso, os horários que eram das $17 \mathrm{~h}$ às $19 \mathrm{e} 30 \mathrm{~h}$, foram alterados, tendo início às $16 \mathrm{e} 30 \mathrm{~h}$ devido ao momento crítico que estamos vivendo, por conta da pandemia do covid-19. Uma doença causada pelo vírus coronavírus Severe Acute Respiratory Syndrome (SARS-CoV-2) que se espalhou pelo planeta, tendo início na China em 31 de dezembro de 2019, matando milhares de pessoas, afetando principalmente idosos e pessoas com comorbidades como hipertensão, diabetes, asma e doenças cardíacas, além de impactar negativamente a economia de todos os países (Ministério da Saúde, 2020). 


\subsection{Comercialização e marketing}

Quando questionado a respeito da divulgação da feira, o presidente relatou que já tentaram fazer panfletagem e anúncios na rádio da cidade, porém não percebeu aumento no número de frequentadores. Citou também um site que eles possuem, mas não soube dizer o endereço da página, julgando não ter conhecimento "dessas coisas", se referindo à internet. De acordo com Thornton (2003), existem algumas barreiras de apropriação da rede entre os agricultores, sendo elas, a idade, o estilo de vida, a situação econômica, a família, a rotina de trabalho e o nível escolar, que interferem na adoção da tecnologia. Dessa forma, projetos para inclusão digital que possibilite a aprendizagem necessária ao indivíduo, a fim de que ele possa interagir nas mídias digitais como consumidor e produtor de seus conteúdos e processos, são essenciais (Rondelli, 2003).

A falta de assistência de agentes externos, como a prefeitura, também dificulta a promoção dos circuitos curtos. De acordo com Leite e Teles (2020), o auxílio da prefeitura na divulgação das feiras livres é de extrema importância, pois ajuda a demonstrar a contribuição que ela traz à cidade. Além disso, em pesquisa com feiras agroecológicas de Recife, eles citam também, a ajuda da Universidade Federal Rural de Pernambuco no processo de assessoria técnica e divulgação das feiras e de trabalhos de base agroecológicas dos agricultores, no programa de rádio, dando maior visibilidade às feiras e aumento de consumidores.

Uma das perguntas feitas ao presidente, foi sobre a feira ser um espaço de sociabilidade. Ele confirmou com veemência que sim, principalmente em relação ao público idoso. Embora, devido à pandemia, os idosos quase não apareçam mais, eles enchiam as bancas e aproveitavam para contar piadas e fazer dali um local de encontro. Era uma festa, segundo o entrevistado. Isso corrobora com Kinjo e Ikeda (2005) que julgam as feiras como locais onde muitas pessoas buscam o convívio social.

Ele reforça que, durante uns 10 anos o principal público eram os idosos e gradativamente isso foi mudando, tendo muitos jovens hoje em dia, perfazendo um público mais igualitário. De acordo com Lima e Fontana (2019), os jovens têm procurado adquirir produtos diretamente do produtor, além de utilizar a feira como local para lanchar. Embora a maioria dos jovens não possua o hábito de comprar em feiras, esse aumento observado é tido como satisfatório, uma vez que isso possa vir a criar valores que irão fidelizar esses consumidores por muito tempo (Specht et al., 2019).

Uma das questões levantadas foi, quais seriam as principais dificuldades encontradas para a realização da feira, e em contrapartida obteve-se como resposta que, seria a falta de apoio das instituições públicas. Ele citou que Marechal Cândido Rondon tem condições para que sejam implantadas pelo menos mais duas feiras em diferentes espaços, apontando um dos locais, próximo ao cemitério e outro, saída para Nova Santa Rosa, como pontos interessantes. Porém para isso, explicou que precisariam de apoio do poder público, pois é preciso executar diversas etapas, desde fazer levantamento de produtores, levantamento de espaço, qual seria a melhor estrutura, fazer um acompanhamento e também boa divulgação, mas ele não percebe muito interesse da parte desses órgãos.

Frente a tal resposta, pode-se perceber a real necessidade de políticas públicas voltadas às famílias agricultoras e acesso a tais políticas, por parte delas. Além de apoio para o funcionamento dos mercados sustentáveis, de modo que as famílias consigam escoar sua produção, e não se sintam levadas a entregar suas mercadorias apenas para o mercado agrícola industrial (Fontana, 2018).

Ele relatou ainda que, há alguns anos atrás a Universidade Estadual do Oeste do Paraná tentou contribuir, no qual diversos alunos do curso de agronomia começaram a fazer o levantamento do número de produtores, no intuito de colaborar para a implantação das outras feiras. No entanto, ele nunca soube se o trabalho foi concluído. Isso nos chama a atenção, tendo em vista que realmente a Universidade é de grande valia para a sociedade, podendo auxiliar no fortalecimento e organização política e em uma gestão mais autônoma (Saquet, 2018). É necessário que as pesquisas sejam participativas, que haja sintonia 
entre pesquisador e pesquisado, devendo ser centradas na realidade e nos problemas apresentados por parte dos indivíduos analisados e que exista retorno dos resultados e conclusões aos envolvidos (Fals Borda, 1981).

Em relação ao preço dos produtos comercializados, segundo o entrevistado, os produtores não têm um consenso, cada um faz seu preço, mas se baseiam ao mercado local. Isso depende da demanda e elasticidade entre queda e aumento da valorização diante da procura por parte dos consumidores, que mostra uma fragilidade pela regulamentação a respeito do preço, levando a uma reflexão sobre a comercialização dos produtos (Vieira \& Sartori \& Moraes \& Siqueira, 2020).

Nesse processo de comercialização dentro da feira, a percepção de produtos duplicados é visível pelo fato de existirem bancas com diversos produtos idênticos, porém, o presidente alega que isso não chega a interferir nas vendas, uma vez que esta comercialização envolve uma relação de confiança entre consumidores e produtores (Araújo \& Ribeiro, 2018).

Em relação ao número de frequentadores, o entrevistado não soube dizer exatamente uma média do fluxo de pessoas que passam pela feira. Isso mostra a existência de uma lacuna que precisa ser preenchida ou uma possibilidade para pesquisa futura. Mas de modo geral, ele consegue fazer um levantamento do quanto cada feirante faz por feira e em cima disso, ele tem uma ideia da quantidade de pessoas, que gira em torno de 1000 quando as feiras são boas. Ele cita ainda que as melhores feiras são quando sai o pagamento da população, sendo que as feiras no fim do mês são mais fracas e destaca uma grande queda no número de pessoas por conta do coronavírus.

Isso se deve ao fato de que em 23 de março de 2020 foi decretado isolamento social do município de Marechal Cândido Rondon, com intuito de enfrentar a pandemia na cidade. Dessa forma os cidadãos, principalmente os que possuem sessenta anos ou mais, devem permanecer em suas residências para evitar o contágio e propagar a doença (Marechal Cândido Rondon, 2020). Sendo assim, por causa dessa medida municipal, realmente foi possível observar, nas visitas que realizamos no local durante a pesquisa, um público menor e mais jovem.

Ao entrevistar 12 consumidores na feira, percebemos que não é apenas uma relação de compras e vendas, mas de consumidores que pretendem ajudar e contribuir para o fortalecimento da comunidade, trazendo um aspecto importante que é valorizar as pessoas do rural, apoiando-os a terem uma renda e reprodução socioeconômica. De maneira geral, os consumidores relataram que compram na feira porque entendem que é uma forma de solidariedade com quem produz fora da cidade, além de aproveitarem a oportunidade de consumir produtos de alta qualidade e naturais.

Quando questionados sobre o que a feira representa, os entrevistados responderam quase que unanimemente, a qualidade de vida e o reconhecimento da feira como patrimônio da cidade, sendo um símbolo do desenvolvimento local, de fraternização e socialização, perfazendo assim uma nova cultura que se define por meio da compreensão e da importância de valorizar os produtos locais rurais.

Nesta ótica, destaca-se a frequência dos consumidores no local. Muitos dos entrevistados disseram que frequentam a feira há 20 anos, participando e comprando todas as semanas e quando faltam, por motivo de força maior, eles sentem falta. Sendo assim, para muitos consumidores, a feira já faz parte da vida deles. Nesse sentido, é de suma importância que as autoridades locais e instituições que estão distantes, se aproximem da feira, a fim de auxiliar no bom funcionamento da mesma. Por fim, a mensagem que os consumidores deixam para a população e dirigentes, é que somos todos responsáveis para fazer o próprio marketing da feira, além de levar mais pessoas a conhecer o local.

\subsection{Relações do ambiente interno e externo da Feira do Produtor Rural: Matriz FOFA e Diagrama de Venn}

Através da aplicação da Matriz FOFA na situação empírica da Feira do Produtor Rural, percebeu-se diversos pontos importantes, sintetizados na Tabela 1. No ambiente interno, os pontos positivos identificados foram, a organização da feira, como principal elemento dinamizador de mudanças e a venda direta ao consumidor, que gera valor imediato, já que os produtos, quando eram repassados a intermediários, tinham os pagamentos efetuados somente ao fim do mês.

Também 
um rico espaço de socialização entre consumidores e agricultores, além de outras possibilidades, como por exemplo, um sorteio de uma cesta básica entre os consumidores, ação que estão testando a fim de aumentar o público. Como fraquezas, percebeu-se a projeção de algumas individualidades entre os agricultores, a necessidade de adaptação do espaço físico da feira, cuja ideia é a ampliação, para a venda de comida e consumo no local. Além da organização do funcionamento da feira, no sentido de contabilizar o fluxo de consumidores e o principal problema, que é o fato da feira não possuir um espaço físico próprio, sendo que o terreno pertence à prefeitura municipal de Marechal Cândido Rondon - PR e o prédio ao Sindicato Rural Patronal de Marechal Cândido Rondon - PR.

Tabela 1 - Sistematização Matriz FOFA da Feira do Produtor Rural de Marechal Cândido Rondon - PR.

\begin{tabular}{|c|c|}
\hline Fortalezas & Fraquezas \\
\hline $\begin{array}{c}\text {. Organização da feira } \\
\cdot \text { Venda direta ao consumidor } \\
\cdot \text { Espaço de socialização } \\
\cdot \text { Satisfação dos agricultores } \\
\text { · Novidades (a ideia da cesta básica ao final do mês) }\end{array}$ & $\begin{array}{c}\text { - Individualidades presentes na organização } \\
\text { · Necessidade de melhor organização na feira } \\
\text { (contabilizar o fluxo de consumidores) } \\
\text { · Adaptações no espaço físico (venda de comidas) } \\
\text { · A feira não possuir um espaço próprio }\end{array}$ \\
\hline Oportunidades & Ameaças \\
\hline $\begin{array}{c}\text { · Divulgações (no rádio, mídias sociais e outros) } \\
\text { - A consolidação da feira como patrimônio histórico } \\
\text { do município, aspecto que já é considerado pelos } \\
\text { consumidores antigos } \\
\text {. Parcerias } \\
\text {. Maior apoio dos órgãos públicos }\end{array}$ & $\begin{array}{l}\text { Percebem que nos dias de feiras, os supermercados } \\
\text { realizam as promoções nos produtos hortícolas; } \\
\text { - Pouco apoio de órgãos públicos, como a secretaria } \\
\text { municipal de Agricultura, Emater e outros. }\end{array}$ \\
\hline
\end{tabular}

Fonte: Pesquisa de campo (2020)

No que se refere aos elementos do ambiente externo, foi identificado como oportunidades, a divulgação da feira em diversos meios de comunicação, cujo entrevistado citou que um amigo por conta própria, começou este mês de junho, divulgar a feira na rádio, após terem a ideia de montar uma cesta básica de alimentos para sortear ao final do mês.

Também se observa a necessidade de que a feira se consolide como patrimônio histórico do município, uma vez que os consumidores mais antigos já a consideram, devido a sua importância e tempo de atuação. Além disso, enfatizam a possibilidade de parcerias e aproximações com órgãos públicos, como aspectos muito benéficos à feira. Por outro lado, as principais ameaças identificadas foram, que geralmente nos dias de realização da feira, os supermercados efetuam grandes promoções, que em grande parte abrangem os produtos hortícolas, também vendidos pelos agricultores, e o pouco apoio de órgãos como a secretaria municipal de agricultura, Emater e outros, que teriam colaborações importantes à feira.

Os aspectos observados indicam a necessidade de diversas ações futuras, pensando no fortalecimento e na longevidade da feira. Como forma de melhor agregação das fortalezas, poder-se-ia discutir processos voltados a estratégias fundamentadas nos princípios do cooperativismo, visando restringir algumas ameaças observadas. Há uma clara necessidade de discutir junto ao poder público, a definição de um lugar próprio para a feira, a fim de que se possa efetuar as chamadas 
adequações físico-estruturais, para atender sua demanda. A ausência de uma infraestrutura própria e de um maior auxílio do poder público também foi encontrada por UENO (2016) em pesquisa realizada em seis feiras no município de Campinas/SP.

Em relação aos aspectos externos, fica bem ilustrado que com as parcerias, novas oportunidades podem ser elaboradas, e por outro lado, um grande desafio a se pensar, é como solucionar a questão da concorrência com os supermercados.

Por sua vez, através do Diagrama de Venn, foi possível observar o grau de importância e interação das diversas instituições e organizações, em relação a feira do Produtor Rural (Figura 3). Entre as indicadas como muito importantes, constam a Secretaria de Agricultura e Política Ambiental (SMAS), a Universidade do Oeste do Estado do Paraná (UNIOESTE), o Sindicato Rural Patronal de Marechal Cândido Rondon - PR e a Empresa de Assistência Técnica e Extensão Rural (EMATER). Como menos importante, o Sindicato dos Trabalhadores Rurais de Marechal Cândido Rondon e com importância intermediária, o Centro de Apoio e Promoção da Agroecologia (CAPA).

Figura 3 - Diagrama de Venn a partir da Feira do Produtor Rural.

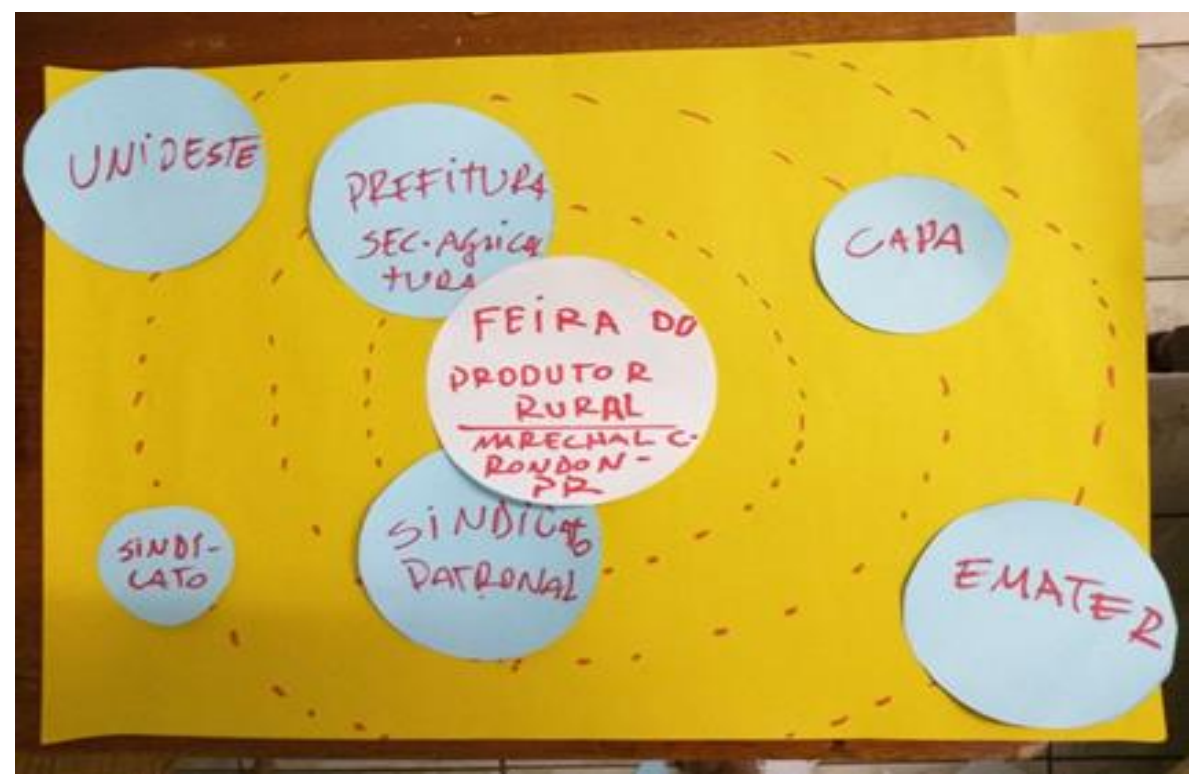

Fonte: Pesquisa de Campo (2020).

No entanto as interações se mostraram bastante diversas. A secretaria de agricultura e o sindicato patronal, indicados como muito importantes, se restringe ao fato de que a primeira cede o terreno e o segundo, a estrutura física, sendo o grau que os aproxima. A UNIOESTE, por já ter desenvolvido diversos trabalhos junto à feira, foi apontada como muito importante, porém no momento, é percebida com grau elevado de distanciamento, pois os agricultores apontam diversas demandas à essa instituição, como ações de marketing, elaboração do histórico da feira, pesquisas, entre outras, que segundo eles, não estão sendo realizadas. A EMATER, que esteve muito presente na formação da feira, inclusive realizou o levantamento e identificação dos agricultores para compor a feira, encontra-se no contexto atual, distante.

Indicam o CAPA com importância intermediária, pelo fato de suas ações estarem mais voltadas ao acompanhamento dos agricultores nas propriedades de produção agrícola. Seu grau de interação também é tido como intermediária, por assessorar duas famílias da feira e contribuir no processo de transição ao sistema agroecológico e orgânico de produção, além de certificações. O sindicato dos trabalhadores rurais, foi citado com pouca importância e grau de interação distante à feira, pois apesar de vários agricultores serem vinculados a essa organização, ainda não conseguiram desenvolver trabalhos juntos. 
Embora pode-se perceber as contribuições das organizações e entidades para com a feira ao longo do tempo, através de maior interação, essa relação vem sendo relativizada. Os agricultores se veem desamparados e percebem nas parceiras, oportunidades de fortalecimento da feira. A nossa hipótese é de que uma maior interação dessas organizações, como as secretarias municipais de educação, cultura e outras, além da recente criação do Instituto de Desenvolvimento Rural do Paraná (IDR-PR), que trata do apoio ao desenvolvimento rural sustentável, contribuem para o fortalecimento da feira enquanto circuito curto de comercialização, na ressignificação da relação, produtores e consumidores.

\section{Considerações Finais}

Esse artigo buscou caracterizar a feira do agricultor rural de Marechal Cândido Rondon/PR e propiciar um olhar sobre suas potencialidades e limitações. Isso foi realizado através de questionários, além da matriz FOFA e do Diagrama de Venn, duas metodologias capazes de responder sobre os limites e potencialidades da feira.

A feira é um importante vetor do desenvolvimento econômico para os feirantes, apesar de necessitar de mudanças em sua infraestrutura física e um melhor diálogo entre os seus membros e os órgãos da ATER (Assistência Técnica e Extensão Rural). Já que o cooperativismo e a parceria entre esses dois atores sociais possibilitam atingir maior público de consumidores, gerando renda para os agricultores e promovendo a economia local.

As potencialidades existentes na feira são o processo organizacional; a compra direta, em circuitos curtos, facilitando a comercialização e aumentando a margem de lucro, enquanto apresenta a individualidade dos feirantes; e a falta de organização entre os consumidores em dia de feira como as principais limitações. Esses resultados são novidades trazidas por esse artigo, tendo em vista que não se tem dados do uso das metodologias usadas na feira em artigos atuais.

Percebe-se que apesar da importância da feira para o município, não existe um diálogo efetivo entre a sua diretoria e os órgãos municipais, a fim de desenvolvê-la socialmente, em um processo que ambas as partes seriam beneficiadas, podendo ser isso um tema para uma próxima pesquisa, uma análise do porquê dessa dificuldade.

Valorizar a agricultura familiar assim como também lhe constituir suporte, não é somente um processo pensando no presente, mas também no futuro, o qual dependerá de novas ações na busca pelo desenvolvimento rural sustentável.

Observa-se a necessidade de pesquisas futuras que busquem analisar as estratégias sustentáveis presentes na feira, com o intuito de realizar um diagnóstico sobre o equilíbrio entre as dimensões econômica, sociocultural e ambiental.

\section{Agradecimentos}

Agradecemos a Universidade Estadual do Oeste do Paraná (UNIOESTE), o CAPES - Coordenação de Aperfeiçoamento de Pessoal de Nível Superior e o CNPq - Conselho Nacional de Desenvolvimento Científico e Tecnológico, pelo financiamento por meio da bolsa dos autores.

\section{Referências}

Araújo, A. M., \& Ribeiro, E. M. (2018). Feiras, feirantes e abastecimento: uma revisão da bibliografia brasileira sobre comercialização nas feiras livres. Estudos Sociedade e Agricultura, 26(3), 561-583.

Assis, R. L. de. (2006). Desenvolvimento rural sustentável no Brasil: perspectivas a partir da integração de ações públicas e privadas com base na agroecologia. Economia Aplicada, 10(1), 75-89. https://dx.doi.org/10.1590/S1413-80502006000100005.

Baiardi, A. (2014). Gênese e evolução da agricultura familiar: desafios na realidade brasileira e as particularidades do semiárido. Revista Econômica do Nordeste, 45(5), 143-156.

Bardin, L. (2011). L'analyse de contenu (3e tirage.). Paris: PUF.

Buainain, A. M. (2006). Agricultura familiar, agroecologia e desenvolvimento sustentável: questões para debate (No. IICA E20-30). IICA. 
Buainain, A. M., \& Batalha, M. O. (2007). Cadeia produtiva de produtos orgânicos (5a ed.). Bib. Orton IICA/CATIE.

Caporal, F. R., \& Costabeber, J. A. (2004) Agroecologia e extensão rural: Contribuições para a promoção do desenvolvimento rural sustentável. MDA/SAF/DATER - IICA.

Cepal, N. (2014). Agricultura familiar y circuitos cortos: Nuevos esquemas de producción, comercialización y nutrición. Memoria del seminario sobre circuitos cortos realizado el 2 y 3 de septiembre de 2013 .

Darolt, M. R., Lamine, C., Brandenburg, A., Alencar, M. de C. F., \& Abreu, L. S. (2016). Redes alimentares alternativas e novas relações produção-consumo na França eno Brasil. Ambiente \& Sociedade, 19(2), 1-22. https://doi.org/10.1590/1809-4422ASOC121132V1922016.

Esquerdo, V. F. de S., Bergamasco, S. M. P. P., \& Andrade, F. R. P. de. (2013). Agricultura Familiar e o PNAE: A implantação da Lei 11.947/2009 nos municípios do circuito das frutas-SP. Retratos de Assentamentos, 16(2), 153-173. https://doi.org/10.25059/25272594/retratosdeassentamentos/2013.v16i2.145.

Fals Borda, O. (1981). Investigación participativa y praxis rural. In: La ciência y el Pueblo. Grossi, F., Gianotten, V., \& Wit, T. (Org.). Mosca Azul, 19-47.

Fontana, A. P. C. (2018). Tecendo relações: a feira da agricultura familiar como espaço para além da comercialização de alimentos. 2018. Dissertação (Mestrado em Desenvolvimento Rural Sustentável) Universidade Estadual do Oeste do Paraná - UNIOESTE - Marechal Cândido Rondon, Brasil.

Gil, A. C. (2008). Métodos e técnicas de pesquisa social (6a ed.). Editora Atlas SA.

Guillen, J. F., Coti-Zelati, P. E., \& de Araújo, D. L. A. (2020). Family Farming And Sustainable Development Of Agribusiness In The Metropolitan Region Of Campinas. Revista Metropolitana de Sustentabilidade, 10(1), 123-145.

Instituto Brasileiro de Geografia e Estatística. (2020). Cidades e Estados - Marechal Cândido Rondon. https://www.ibge.gov.br/cidades-eestados/pr/marechal-candido-rondon.html.

Instituto Brasileiro de Geografia e Estatística. IBGE mapas. (2010). ftp://geoftp.ibge.gov.br/organizacao_do_territorio/malhas_territ oriais/malhas_de_setores_censitarios_divisoes_intramunicipais/censo_2010.

Instituto Paranaense de Desenvolvimento Econômico Social. (2020). Caderno estatístico - Município de Marechal Cândido Rondon. http://www.ipardes.gov.br/cadernos/MontaCadPdf1.php?Municipio=85960\&btOk=ok.

Jarosz, L. (2008). The city in the country: Growing alternative food networks in Metropolitan areas. Journal of rural studies, 24(3), 231-244.

Kinjo, T., \& Ikeda, A. (2005). Comportamento do consumidor em feiras livres. CEP, 7195, 120. In: Congresso da sociedade brasileira de economia e sociologia rural. Brasília. Anais.

Kummer, L. (2007). Metodologia participativa no meio rural: uma visão interdisciplinar. conceitos, ferramentas e vivências. Salvador: GTZ.

Lago, A., Lengler, L., Coronel, D., \& Silva, T. (2006). Agricultura familiar de produtos orgânicos: um olhar sob a ótica do marketing. Extensão Rural, O(13), 93-116. Recuperado de https://periodicos.ufsm.br/extensaorural/article/view/5606

Lakatos, E. M., \& Marconi, M. de A. (1996). Fundamentos de Metodologia científica. (3a ed). Atlas.

Lei da agricultura familiar $\mathrm{n}^{\circ} 11.326$ de 24 de julho de 2006. http://www.planalto.gov.br/ccivil_03/_Ato2004-2006/2006/Lei/L11326.htm.

Leite, D. C., \& Teles, E. C. P. V. A. (2020). Comercialização de produtos agroecológicos a partir de circuitos curtos: a experiência das feiras agroecológicas de Recife, Pernambuco. EXTRAMUROS -Revista de Extensão da UNIVASF, 7(2), 026-044.

Lima, R., \& Fontana, A. (2019). As feiras da agricultura familiar como território de práticas alimentares e sociabilidades. Redes (St. Cruz Sul, Online), 24(3), 75-100. https://doi.org/10.17058/redes.v24i3.14119.

Luciano, W. R. (2017). Agricultura familiar no contexto da Feira do Produtor Rural Feira Corujão no município de Rio Claro-SP. Monografia em geografia, Universidade Estadual Paulista Júlio de Mesquita Filho, Rico Claro, Brasil. https://repositorio.unesp.br/bitstream/han dle/11449/157034/000906640.pdf?sequence=1\&isAllowed=y.

Marechal Cândido Rondon. (2020). Decreto número 105/2020 de 08 de abril de 2020. https://leismunicipais.com.br/a/pr/m/marechal-candido-rondon/decreto.

Messmer, J. G. (2013). Les circuits courts multi-acteurs: émergence d'organisations innovantes dans lês filières courtes alimentares. Rapport INRA-MaR/S.

Ministério da Saúde. (2020). Sobre a doença. https://coronavirus.saude.gov.br/sobre-a-doenca\#o-que-e-covid.

Moreira, R. J. Terra, poder e território. (2007). Expressão Popular.

Oliveira, É. D. (2018). O lugar da produção e consumo em circuitos curtos. Revista de Gestão e Organizações Cooperativas, 5(10), 65-78. https://doi.org/10.5902/2359043229113.

Oliveira, P. S., \& Marjotta-Maistro, M. (2016). Canais de comercialização de orgânicos: alternativas para os agricultores familiares do leste paulista. Revista Brasileira de Gestão e Desenvolvimento Regional, 12(3). https://www.rbgdr.net/revista/index.php/rbgdr/article/view/2515/535.

Organização das Nações Unidas para Agricultura e Alimentação. (2020). Caderno de Formação - Desenvolvimento Rural Sustentável. 2012. <http://www.fao.org/3/aq096pt/aq096pt.pdf>.

Organização das Nações Unidas. (2020). O Programa das Nações Unidas para o Meio Ambiente (PNUMA). https://nacoesunidas.org/agencia/pnuma/. 
Research, Society and Development, v. 10, n. 1, e20310111462, 2021 (CC BY 4.0) | ISSN 2525-3409 | DOI: http://dx.doi.org/10.33448/rsd-v10i1.11462

Pecqueur, B. (2006). O desenvolvimento territorial. Raízes: Revista De Ciências Sociais E Econômicas, 24(1 e 2), 10-22. https://doi.org/10.37370/raizes.2005.v24.243

Pereira, A. S., Shitsuka, D. M., Parreira, F. J. \& Shitsuka, R. (2018). Metodologia Da Pesquisa Científica. UAB/NTE/UFSM.

Pereira, V., Brito, T., \& Pereira, S. (2017). A feira-livre como importante mercado para a agricultura familiar em Conceição do Mato Dentro (MG). Revista Ciências Humanas, 10(2). https://doi.org/10.32813/rchv10n22017artigo6.

Pierri, M. C. Q. M., \& Valente, A. L. E. F. (2015). A feira livre como canal de comercialização de produtos da agricultura. In $53^{\circ}$ Congresso de Economia e Sociologia Rural. Alagoas.

Rondelli, E. (2003). Quatro passos para a inclusão digital. Sete pontos. http://www. comunicacao. pro. br/setepontos/5/4passos. Htm.

Saquet, M. A. (2018). A Perspective of Counter-Hegemonic Analysis and Territorial Transformation. Geographica Helvetica, 73(4), $347-355$.

Schneider, S., \& Cassol, A. (2013). A agricultura familiar no Brasil. Porto Alegre, Relatório de pesquisa. FIDA/RIMISP.

Secretaria da Agricultura Familiar e Cooperativismo. (2020). O que é agricultura familiar? http://sistemas.agricultura.gov.br/vitrine/o-que-e-a-agriculturafamiliar\#: :text=O\%20que\%20\%C3\%A9\%20a\%20agricultura,de $\% 20 \mathrm{~m} \% \mathrm{C} 3 \%$ A3o\%20de\%20obra\%20familiar.

Silva, B. J. Circuitos curtos de comercialização de produtos orgânicos: emancipação socioeconômica na agricultura familiar? (2015). Dissertação em agrossistemas, Universidade Federal de Santa Catarina, Brasil.

Specht, S., Blume, R., Ende, M., \& Souza, M. (2019). É dia de fazer feira na Universidade: análise do perfil do consumidor da Polifeira. Redes (St. Cruz Sul, Online), 24(3), 183-197. https://doi.org/10.17058/redes.v24i3.14124.

Tauk Santos, M. S. (2000). Comunicação rural - velho objeto, nova abordagem: mediação, reconversão cultural, desenvolvimento local. In: Comunicação e informação: identidades e fronteiras. Lopes, M. I. V., Frau-Meigs, D. (Org.). Bagaço.

Thornton, R. (2003). El agricultor, Internet y las barreras a su adopción. In: La extensión rural en debate: concepciones, retrospectivas, cambios y estratégias para el Mercosur. Thornton, R., \& Cimadevilla, G. (Ed.). INTA, 323-345.

Ueno, V., Fagundes, G., \& Habib, M. (2016). Análise comparativa entre feiras orgânicas e convencionais, no município de Campinas (SP). Cadernos De Agroecologia, 10(3). http://revistas.aba-agroecologia.org.br/index.php/cad/article/view/19848.

Vieira, A. N. de C., Sartori, A., Moraes, F. C. de, \& Siqueira, R. N. de. (2020). A elasticidade de transmissão de preços entre os elos de mercado: produtor, atacado e varejo na comercialização da carne bovina no período de 1997 a 2013. Revista Estudos e Pesquisas em Administração,4(2), 65-80. https://doi.org/10.30781/repad.v4i2.10069.

Wanderley, M. N. B. (2000). A valorização da agricultura familiar e a reivindicação da ruralidade no Brasil. Revista Desenvolvimento e Meio Ambiente, n. 2. 